\section{SUGAR TAX EARNS ITS STRIPES, NOW EXPAND AND RING FENCE PROCEEDS}

Research confirming the effectiveness of the sugar tax has been welcomed by the British Dental Association, but warned the real benefits will be lost unless government shows its willingness to expand the levy and ring-fence proceeds to tackle child tooth decay and obesity.

The study by academics at the University of Oxford, University of Cambridge, London School of Hygiene and Tropical Medicine, Exeter, Warwick and Bath Universities published in PLoS Medicine, finds clear evidence of manufacturers lowering sugar levels in drinks in response to the introduction of the levy.

The analysis shows when former Chancellor George Osborne announced plans to introduce the tax, around $52 \%$ of eligible soft drinks contained $5 \mathrm{~g}$ or more sugar per $100 \mathrm{ml}$ and were liable for the tax. The levy came into force in April 2018, and by February 2019, only $15 \%$ of soft drinks were still liable.

A recent study found a $29 \%$ reduction in the total amount of sugar sold in soft drinks in the UK from 2015-2018, as a direct result of industry reformulating products to avoid exposure to the tax.

While the Soft Drinks Industry Levy is now forecast to raise $£ 340$ million in 2020 21, dentists have expressed concerns that the last Spending Round announcement failed to make any commitment to ring- fence revenue for spending on preventive programmes in children.

The BDA has supported expansion of the levy, to include milk-based drinks and other products both to encourage reformulation, and encourage behaviour change among consumers. While the original levy was meant to be targeted towards school sports, dentists have long advocated expansion into oral health programmes. Tooth decay remains the number one reason for hospital admissions among young children.

Effective long-term investment in early years oral health programmes in nurseries and primary schools in Scotland has shaved millions off treatment costs. While these policies have been adopted in nations from Chile to Israel, the vast majority of local authorities in England lack resources to embrace similar models, with $85 \%$ facing cuts to public health budgets.

BDA Chair Mick Armstrong said: 'The sugar tax has earned its stripes as a weapon in the arsenal of any government interested in tackling preventable disease among children.

'The question now is, are ministers prepared to follow the evidence, double down and really reap the benefits?

'If we're going to win the war against obesity and tooth decay revenues from an expanded levy must be ring-fenced, not left plugging holes in other budgets.'

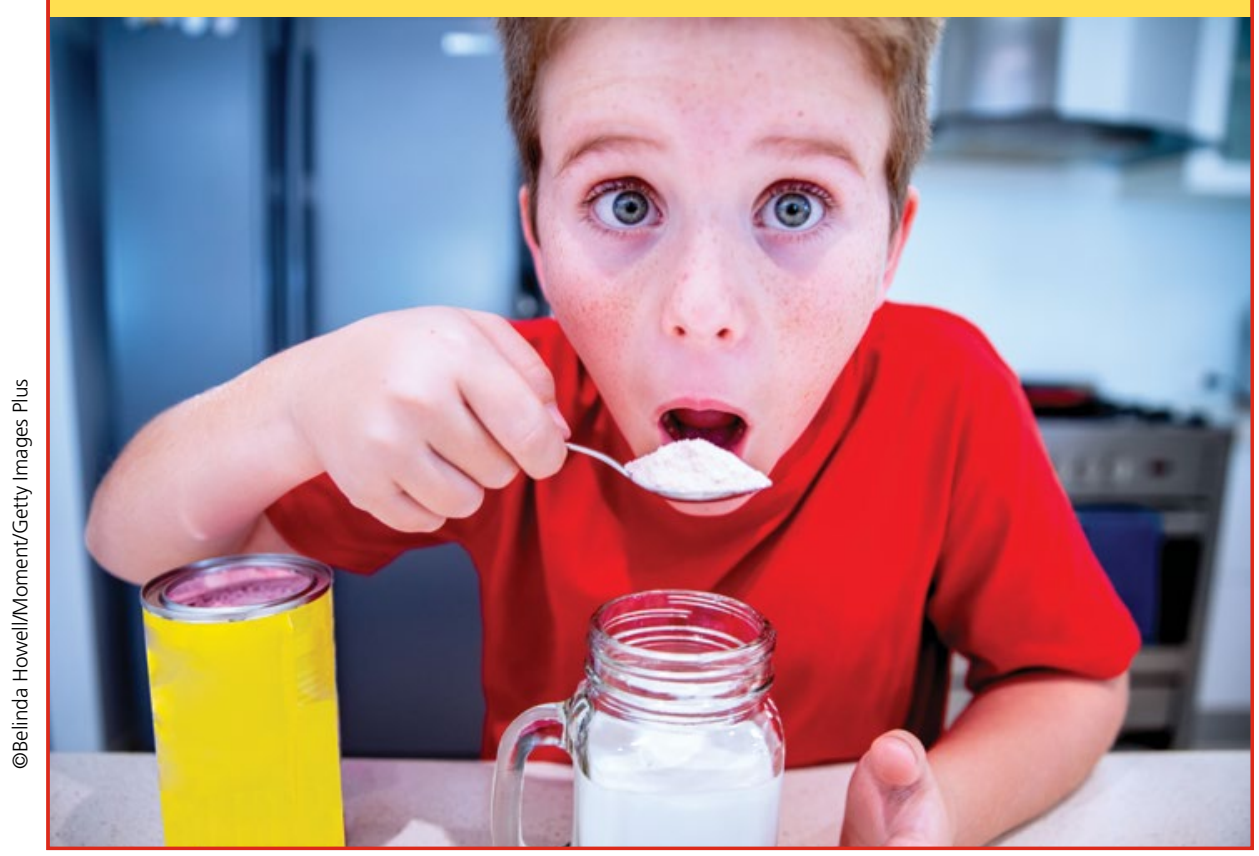

PUBLIC MUST BE ALERT TO DANGERS OF ILLEGAL TEETH WHITENERS AND FAKE TRAINING SCHOOLS

A BBC investigation revealing the scale of illegal teeth whitening highlighted a $26 \%$ rise in the past year.

Undercover reporters from BBC London TV news filmed training schools and companies offering to provide fake whitening qualifications to candidates after just a few hours of training, and putting the public at risk. One school said it had trained 'thousands' of candidates.

The BBC's film unveils the underhand tactics used by unscrupulous companies to lure naive beauticians and others into believing that they can circumvent the law, when only dental professionals registered with the General Dental Council can legally carry out teeth whitening in the UK.

The schools provide rudimentary guidance for illegal whitening, teaching beauticians and hairdressers how to use whitening gels, powerful heating lights and what treatment and dental advice to offer to customers. The BDA has called on the public to remain alert to the risks.

The BDA also calls on the beauty industry to do more to ensure that its members, and those who train them, are aware that providing teeth whitening treatments can only legally be carried out by a registered dentist or dental care professional.

The BDA's scientific advisor, Professor Damien Walmsley, said: 'Illegal whitening is now running rampant across the UK, and while authorities are doing what they can it's vital that the public understand the risks.

'We know that sham teeth whitening schools exploit the ignorance of beauticians and others who are unaware that they could end up in a criminal court. Not just that, these untrained operators can permanently damage your teeth and gums and can't provide help if something goes wrong.

'The public need to be aware that fly-bynights with a few hours online training can cause lasting damage to your teeth and gums and can't help you when something goes wrong.

'If you put yourself in the hands of unqualified individuals armed with unsafe chemicals then you are gambling with your health.

'For safe, effective whitening visit your dentist.' 